\title{
SF3B1 mutation is a prognostic factor in chronic Iymphocytic leukemia: a meta-analysis
}

\author{
Zhenghao Zhang ${ }^{1}$, Shu Chen ${ }^{2}$, Shuang Chen ${ }^{1}$, Gang Chen ${ }^{1}$, Rui Zhang ${ }^{1}$, Jinhua $\mathbf{L i}^{1}$ \\ and Jianhua $\mathbf{Q} \mathbf{u}^{1}$ \\ ${ }^{1}$ Centre of Hematology, The First Affiliated Hospital of Xinjiang Medical University, Urumqi 830054, China \\ ${ }^{2}$ Department of Pathology, The First Affiliated Hospital of Xinjiang Medical University, Urumqi 830054, China \\ Correspondence to: Jianhua Qu, email: jhuaqu@163.com
}

Keywords: SF3B1, chronic lymphocytic leukemia, prognosis, survival, meta-analysis

Received: December 01, $2016 \quad$ Accepted: May 27, $2017 \quad$ Published: July 22, 2017

Copyright: Zhang et al. This is an open-access article distributed under the terms of the Creative Commons Attribution License 3.0 (CC BY 3.0), which permits unrestricted use, distribution, and reproduction in any medium, provided the original author and source are credited.

\section{ABSTRACT}

Recent studies suggest that SF3B1 might be related to poor prognosis in CLL, but the results remain controversial. This meta-analysis was performed to clarify the relationship between SF3B1 mutation and prognosis in patients with CLL. The relevant published reports were searched in PubMed, EMBASE, and Web of Science. A total of $\mathbf{1 3}$ articles were included in this meta-analysis as they met the inclusion and exclusion criteria. The hazard ratios (HRs) and corresponding $95 \%$ confidence intervals (95\%CIs) for progression free survival (PFS) and/ or overall survival (OS) were extracted from each eligible study. The pooled HR evaluating SF3B1 mutation on PFS was 1.81 (95\%CI 1.33-2.46, $I^{2}=78.9 \%, P<0.001$ ) and on on OS was $2.57\left(95 \% \mathrm{CI} 1.68-3.94, \mathrm{I}^{2}=79.3 \%, \mathrm{P}<0.001\right)$ by random effects model. In conclusion, SF3B1 mutation was significantly associated with poor PFS and $O S$ in CLL. It could be consider as a potential prognostic factor in patients with CLL.

\section{INTRODUCTION}

Chronic lymphocytic leukemia (CLL) is a clinical and biological heterogeneous malignant disease characterized by an accumulation of monoclonal $\mathrm{CD} 19^{+} \mathrm{CD} 5^{+} \mathrm{CD} 23^{+}$mature small B-lymphocytes in bone marrow, blood, and lymphoid tissues [1]. Some patients show an indolent clinical course without requiring special therapy, while others having an aggressive course and short survival despite following intensive treatment [2-4]. Therefore, It is very important for us to identify prognostic factors, which could precisely predict the survival and disease progression and choose the reasonable treatment and preventive measures for patients with CLL [5-7]. Some of the cytogenetic and molecular biomarkers, such as TP53 disruption and immunoglobulin heavy chain variable region (IGHV) mutational status, $C D 38$ and ZAP-70 expression, have been proved to be associated with the prognosis of CLL
[8-12]. Even with these biomarkers, however, prediction of the survival and disease progression is not highly reliable.

Splicing factor 3B subunit $1(S F 3 B 1)$ is locate on chromosome 2q33.1. The cDNA is 43074 bp long and comprises 25 exons. The $S F 3 B 1$ protein is part of the spliceosome machinery and plays an important effect of RNA splicing [13]. In western countries, $S F 3 B 1$ mutation was detected in about $5-18 \%$ of newly diagnosed CLL patients [14-15]. Recent data suggest that $S F 3 B 1$ has been reported as one of the prognostic markers in CLL [16-18]. However, the prognosis of SF3B1 mutation in CLL patients was still controversial. Some studies showed that $S F 3 B 1$ mutation have been associated with a relatively poor prognosis, whereas other studies suggested no significant prognostic value in CLL [19, 24]. Thus, it is necessary to perform a meta-analysis to further clarify the relationship between $S F 3 B 1$ mutation and prognosis in patients with CLL. 


\section{RESULTS}

\section{Selection and characteristics of the studies}

Figure 1 showed a flow diagram of the literature selection process. Through the initial database search, a total of 113 studies were included for detailed screening. After excluding non-clinical studies and reviews by reading titles and abstracts, 25 articles were considered potentially eligible and were retrieved in full text. After having excluded of non-survival analysis data or fail to get applicable hazard ratios(HRs) and their 95\% confidence intervals(95\% CIs), 13 articles [16, 19-30] were included in this meta-analysis as they provided at least one of the survival data, progression free survival (PFS) or overall survival (OS). Characteristics of the eligible studies were shown in Table 1.

\section{Association between SF3B1 mutation and OS/ PFS of CLL in total population}

The meta-analysis results of PFS of CLL were shown in Figure 2a. A total of 11 studies with available HRs and their 95\% CIs for PFS have been included in the meta-analysis, with a total of 3505 CLL patients, 422 patients were mutant $S F 3 B 1$ and other 3083 patients were wild-type $S F 3 B 1$. Overall, the pooled HR evaluating SF3B1 mutation on PFS was $1.81(95 \%$ CI $1.33-2.46$, $P<0.001)$ by random effects model for the existence of a significant heterogeneity $\left(\mathrm{I}^{2}=78.9 \%, \quad P<0.001\right)$, which suggested that $S F 3 B 1$ mutation was significantly associated with worse prognosis for CLL in PFS (Figure 2A).

The meta-analysis results of OS of CLL were shown in Figure 2b. 11 studies with available HRs and their 95\% CIs for OS have been included in the meta-analysis, with a total of 3175 CLL patients, 346 patients were mutant $S F 3 B 1$ and other 2829 patients were wild-type $S F 3 B 1$. For the existence of a significant heterogeneity $\left(\mathrm{I}^{2}=79.3 \%\right.$, $P<0.001$ ), random effects model were used in the analysis. Overall, the pooled HR for the 11 eligible studies evaluating SF3B1 mutation on OS was $2.57(95 \%$ CI 1.68 $3.94, P<0.001$ ), which suggested that $S F 3 B 1$ mutation was significantly associated with worse prognosis for CLL in OS (Figure 2B).

\section{Prognostic impact of $S F 3 B 1$ mutation in different subgroups}

For the existence of a significant heterogeneity, the HRs for PFS and OS were pooled in different groups by random effects model. To explain the heterogeneity,

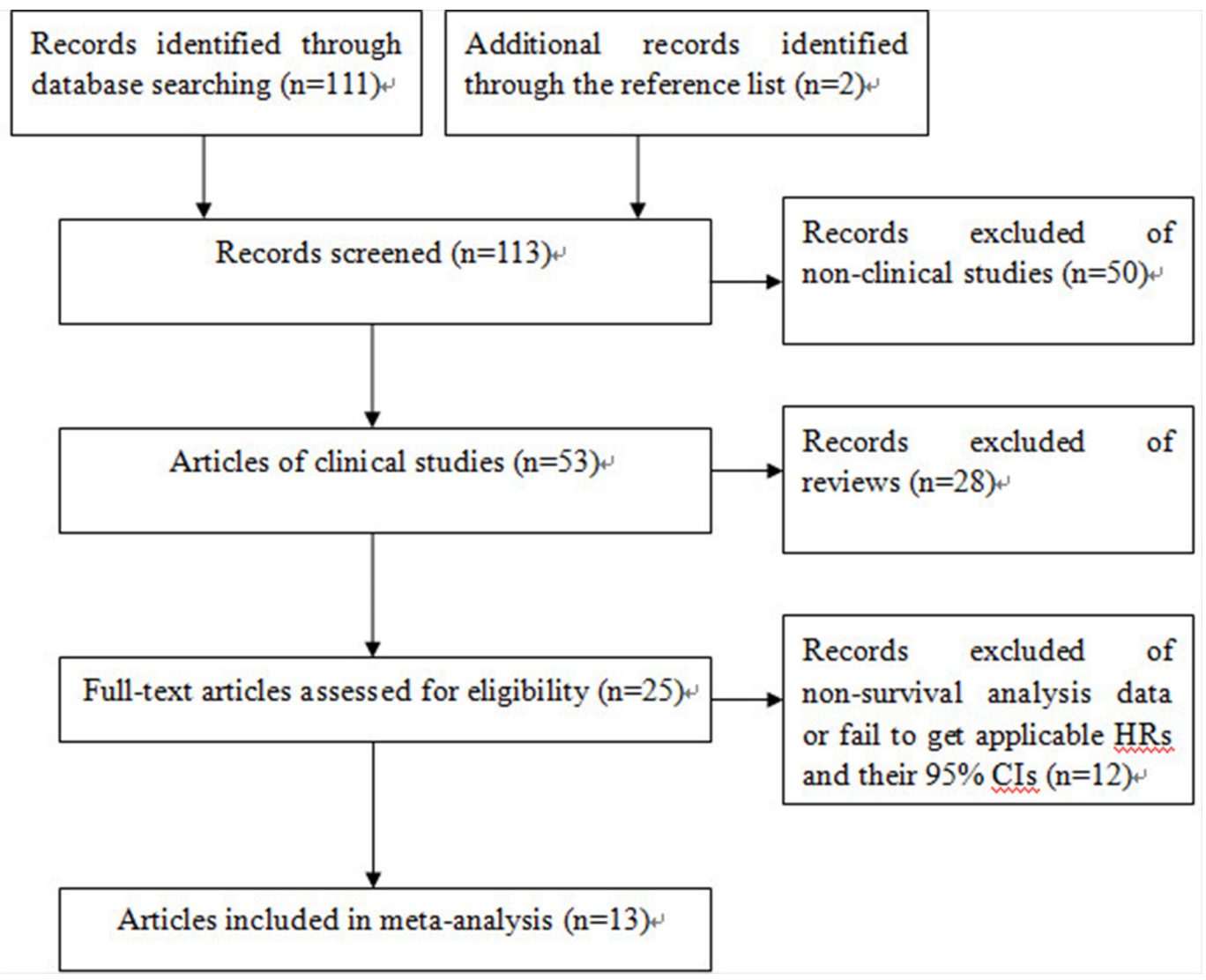

Figure 1: Study flow diagram of included studies. 
Table 1: Characteristics of the eligible studies

\begin{tabular}{|c|c|c|c|c|c|c|c|}
\hline First author & year & $\begin{array}{l}\text { Patients } \\
\text { source }\end{array}$ & $\begin{array}{c}\text { Mutated N } \\
\text { (PFS/OS) }\end{array}$ & $\begin{array}{c}\text { Wild-type N } \\
\text { (PFS/OS) }\end{array}$ & Methods & Outcomes & $\begin{array}{c}\text { Data } \\
\text { extraction }\end{array}$ \\
\hline Nadeu F & 2016 & Spain & $51 / 50$ & $350 / 343$ & NGS & OS/PFS & $\begin{array}{c}\text { Kaplan-Meier } \\
\text { curve }\end{array}$ \\
\hline Rossi D & 2011 & Italy & $17 / 17$ & $284 / 284$ & SS, NGS & OS/PFS & Direct (M) \\
\hline Oscier DG & 2013 & $\begin{array}{l}\text { United } \\
\text { Kingdom }\end{array}$ & $73 / 73$ & $364 / 364$ & HRMA & OS/PFS & Direct (M) \\
\hline Dreger P & 2013 & Germany & $26 / 26$ & $74 / 74$ & DHPLC, SS & OS/PFS & Direct (M) \\
\hline Hurtado AM & 2015 & Spain & $10 / 10$ & $170 / 170$ & NGS & OS/PFS & Direct (M) \\
\hline Stilgenbauer S & 2014 & Germany & 114/NA & $507 / \mathrm{NA}$ & DHPLC, SS & PFS & Direct (M) \\
\hline Mitsui T & 2016 & Japan & $\mathrm{NA} / 7$ & NA/80 & $\mathrm{SS}$ & OS & Direct (M) \\
\hline Jeromin $\mathrm{S}$ & 2014 & Germany & $80 / 80$ & $841 / 841$ & $\mathrm{SS}, \mathrm{NGS}$ & OS/PFS & Direct (M) \\
\hline Wang LL & 2011 & USA & $14 / \mathrm{NA}$ & 77/NA & NGS & PFS & Direct (M) \\
\hline Schnaiter A & 2013 & Germany & $17 / 17$ & $77 / 77$ & DHPLC, SS & OS/PFS & $\begin{array}{c}\text { Kaplan-Meier } \\
\text { curve }\end{array}$ \\
\hline Quesada V & 2012 & Spain & $10 / 10$ & $95 / 95$ & NGS & OS/PFS & $\begin{array}{c}\text { Kaplan-Meier } \\
\text { curve }\end{array}$ \\
\hline Xia Y & 2014 & China & $10 / 15$ & $244 / 292$ & SS & OS/PFS & $\begin{array}{c}\text { Kaplan-Meier } \\
\text { curve }\end{array}$ \\
\hline Rossi D & 2013 & Italy & $\mathrm{NA} / 41$ & NA/542 & $\mathrm{SS}, \mathrm{NGS}$ & OS & Direct $(\mathrm{M})$ \\
\hline
\end{tabular}

NGS: next generation sequencing SS: Sanger sequencing HRMA: high-resolution melt analysis DHPLC: denaturing high performance liquid chromatography NA: not applicable.

we performed a subgroup analysis in patients source, sample number, method and data extraction (Table 2, Supplementary Figures 1-4). In the analysis of PFS, a part of the heterogeneity could be explained by sample number and detection methods, and in the analysis of OS, a part of the heterogeneity could be explained by patients source, sample number, detection methods and data extraction methods. In addition, there was no statistically significant association between the prognosis of CLL and $S F 3 B 1$ mutation in small sample size subgroup, PFS $\mathrm{HR}=0.93(0.48-1.81)$ and $\mathrm{OS} H R=1.53(0.74-3.18)$, and this also could be found in PFS of PCR-based methods group. Besides, we still observed a significant adverse impact of SF3B1 mutation on PFS and OS in other subgroups.

\section{Sensitivity analysis}

We performed sensitivity analysis by sequentially excluding studies to verify the stability of results. The data about PFS and OS of total studies was used to do sensitive analysis. As shown in Figure 3, regarding the sensitivity analysis, the influence of each study on the pooled HR in CLL patients was examined by repeating the meta-analysis, while excluding a single study at a time.
As for the association of $S F 3 B 1$ mutation with the worse prognosis of patients with CLL, the sensitivity analysis suggested that no individual study significantly altered the pooled HR.

\section{Publication bias}

Begg's test and Begg's funnel plot were used for assessment of publication bias in the meta-analysis. As shown in Figure 4, Visual inspection of the Begg's funnel plots of PFS and OS were no substantial asymmetry. The Begg's test for publication bias in the meta-analysis demonstrated no significant publication bias.

\section{DISCUSSION}

With the development of next-generation sequencing technology, more and more biomarkers have been found to play a key role in diagnosis and prognosis of malignancy [31]. In 2011, Wang et al. performed next-generation sequencing of whole exomes and whole genomes on 91 patients with chronic lymphocytic leukemia. Nine genes that were mutated at significant frequencies were identified. Five of the genes with significant mutation 
frequencies had not be reported in CLL. Among these genes, $S F 3 B 1$ was the second most frequently mutated gene with mutations occurring in $15 \%$ of patients [16]. After this, more researches have researched the prognostic significance of $S F 3 B 1$ mutation in CLL patients. Some of them suggested that $S F 3 B 1$ mutation were associated with a poor prognosis, but the results were still conflicting and heterogeneous [19, 24, 28]. To our knowledge, our present study is the first meta-analysis to investigate the association between $S F 3 B 1$ mutation and prognosis in patients with CLL. we believe that our analysis will provide useful information for decision-making in CLL clinically.

The meta analysis combined 13 publications including 3505 patients for PFS and 3175 patients for OS, indicating the correlation between $S F 3 B 1$ mutation and prognosis of CLL. The overall pooled HR revealed that $S F 3 B 1$ mutation was associated with poor prognosis on PFS $(\mathrm{HR}=1.81,95 \% \mathrm{CI} 1.33-2.46)$ and $\mathrm{OS}(\mathrm{HR}=2.57$, $95 \%$ CI 1.68-3.94) in patients with CLL. SF3B1 is a critical component of both major and minor spliceosomes, which enact the precise excision of introns from premRNA. The biological mechanism of SF3B1 mutation in CLL is unclear. Recent studies suggested that SF3B1 could control cell-cycle and apoptosis by alter the splicing. SF3B1 mutations lead to mistakes in the splicing of some specific transcripts that affect the pathogenesis of chronic lymphocytic leukemia.

However, a significant heterogeneity of the included studies was observed in this meta-analysis, so we used subgroup analysis and sensitivity analysis to elucidate the source of heterogeneity. We made the subgroup analysis about patients source for the possible heterogeneity of patients from different regions. Most of the studies were from European countries, only 2 studies were from Asia, 1 from the USA. In this subgroup analysis, the studies from European countries and USA were merged into one group.
A significant correlation of SF3B1 mutation with PFS and OS was observed in the caucasian subgroup. In the subgroup analysis of PFS, only one study was divided into Asia group (HR 1.87, 95\% CI 0.92-3.80), which suggested that there was no statistically significant associations between $S F 3 B 1$ mutation and PFS of CLL patients. But SF3B1 mutation was significantly correlated with poor OS of CLL in Asia (HR 7.14, 95\%CI 2.32-21.93). This discrepancy might be caused by less studies of Asian, so more studies should further be needed in CLL patients of Asia.

Subgroup analysis indicated that sample size might account for part of included studies heterogeneity. Moreover, subgroup analysis indicated that SF3B1 mutation was significantly correlated with poor PFS and OS of patients in subgroup of sample size $>100$ while not in subgroup of sample size $\leq 100$. SF $3 B 1$ mutation patients in studies of sample size $\leq 100$ were too few, which could be a part of the reason for the discrepancy.

Furthermore, SF3B1 mutation detection was performed by using one or more of the following methods: high-resolution melt analysis, denaturing high performance liquid chromatography, Sanger sequencing, or next generation sequencing. The sensitivity for the individual methods were different, it could be one of potential sources resulting in heterogeneity of included studies. According to the basic theory of detection methods, we divided the studies into two subgroups: sequencing-based and PCR-based. The subgroup analysis indicated that detection methods might also account for part of the heterogeneity, and the pooled results form PCR-based methods showed SF3B1 mutation was no significantly correlated with PFS, but this could not be observed in OS.

If HRs and their corresponding CIs were not directly reported in the included studies, the available survival data was extracted from survival curve by using

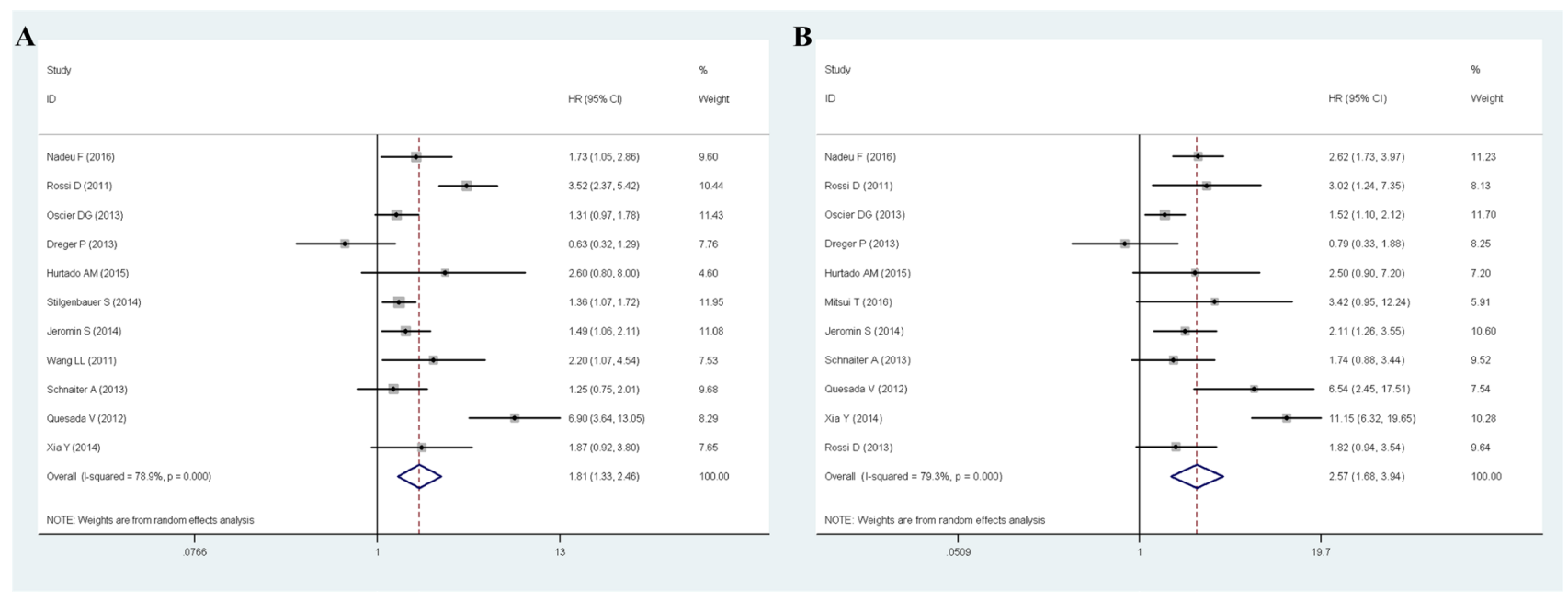

Figure 2: Meta-analysis of the association between SF3B1 mutation and PFS (A) / OS (B) of CLL. 
Table 2 Subgroup analysis of association between SF3B1 expression and prognosis of CLL

\begin{tabular}{|c|c|c|c|c|c|c|c|c|}
\hline & \multicolumn{4}{|c|}{ PFS } & \multicolumn{4}{|c|}{ OS } \\
\hline & No. & HR(95\%CI) & $\mathbf{P}$ & $I^{2}(\%)$ & No. & HR(95\%CI) & $\mathbf{P}$ & $I^{2}(\%)$ \\
\hline \multicolumn{9}{|l|}{ Patients source } \\
\hline Caucasian & 10 & $1.81(1.30-2.51)$ & $<0.001$ & 80.9 & 9 & $2.05(1.53-2.75)$ & 0.050 & 48.4 \\
\hline Asia & 1 & $1.87(0.92-3.80)$ & - & - & 2 & $7.14(2.32-21.93)$ & 0.098 & 63.5 \\
\hline \multicolumn{9}{|l|}{ Sample size } \\
\hline$\leq 100$ & 2 & $0.93(0.48-1.81)$ & 0.116 & 59.6 & 3 & $1.53(0.74-3.18)$ & 0.145 & 48.3 \\
\hline$>100$ & 9 & $2.08(1.49-2.90)$ & $<0.001$ & 79.1 & 8 & $3.01(1.82-4.96)$ & $<0.001$ & 82.8 \\
\hline \multicolumn{9}{|l|}{ Detection methods } \\
\hline Sequencing-based & 7 & $2.49(1.63-3.80)$ & 0.001 & 74.1 & 8 & $3.40(2.08-5.55)$ & $<0.001$ & 74.1 \\
\hline PCR-based & 4 & $1.24(0.99-1.54)$ & 0.239 & 28.9 & 3 & $1.44(1.05-1.97)$ & 0.329 & 10.1 \\
\hline \multicolumn{9}{|l|}{ Data extraction } \\
\hline Direct & 7 & $1.61(1.15-2.26)$ & $<0.001$ & 76.6 & 7 & $1.79(1.36-2.36)$ & 0.287 & 18.7 \\
\hline Kaplan-Meier curve & 4 & $2.26(1.11-4.60)$ & $<0.001$ & 83.6 & 4 & $4.20(1.78-9.92)$ & $<0.001$ & 87.0 \\
\hline
\end{tabular}

A

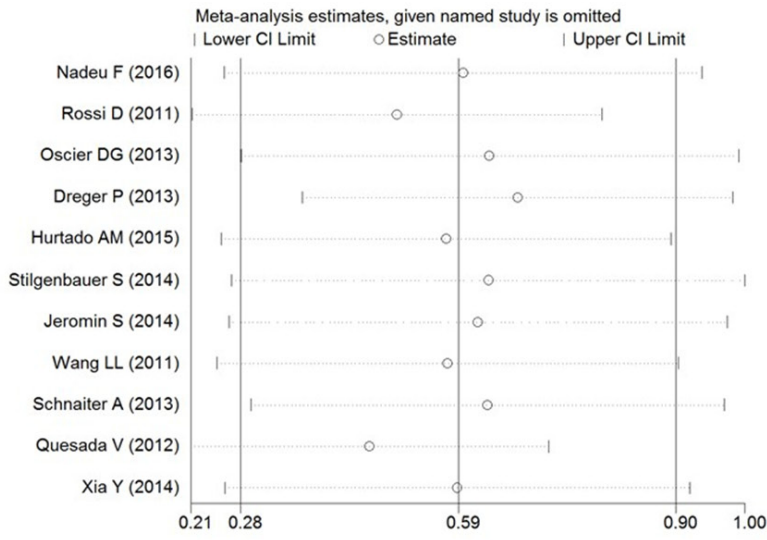

B

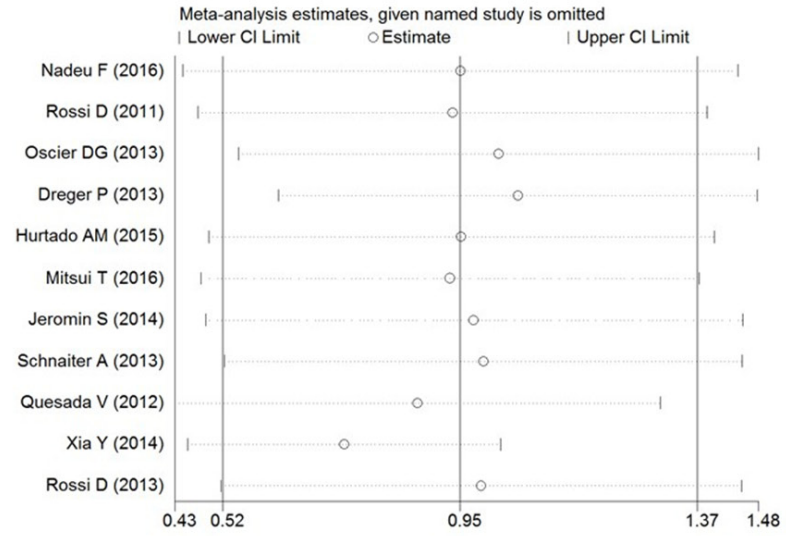

Figure 3: Sensitivity analysis of the association between SF3B1 mutation and PFS (A) / OS (B) of CLL.
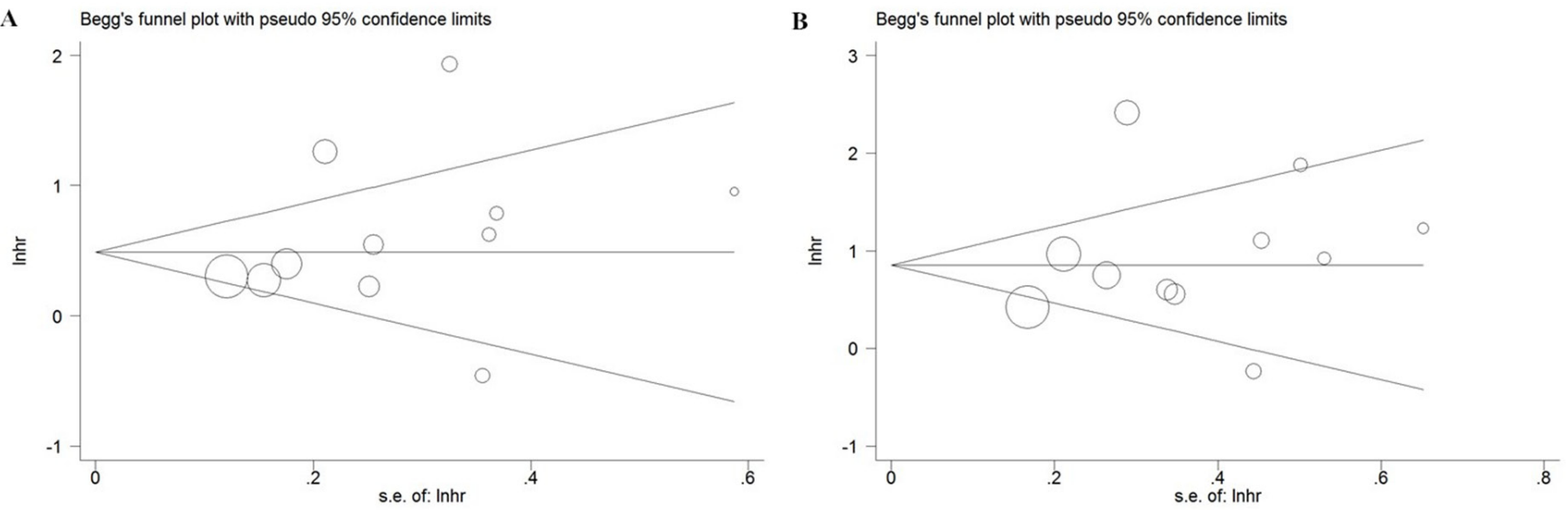

Figure 4: Funnel plot of the association between SF3B1 mutation and PFS (A) / OS (B) of CLL. 
the data extraction software. In order to find the possible heterogeneity of patients from different data extraction methods, we also made the subgroup analysis about data extraction methods. Subgroup analysis indicated that data extraction might also account for part of the heterogeneity. Study results of the survival data were reported by multivariate and univariate analysis. In this study, all of the data of direct extraction was collected from multivariate analysis. In addition to these reasons, heterogeneity might derive from the patients with different clinical stage and type of treatments, due to the limitation of reported data $[32,33]$, we had not made a detailed analysis in this metaanalysis.

In sensitivity analysis, omission of any individual study did not reduce the heterogeneity or help to elucidate the source of heterogeneity [34]. A single study involved in the meta-analysis was deleted each time to reflect the influence of the individual data set to the pooled HR, and the corresponding pooled HR were not materially altered.

Publication bias is another important factor to be considered for all forms of meta-analysis [35]. The Begg's tests and funnel plots for publication bias in the meta-analysis indicated no significant publication bias. However, it should be noticed that some of limitations should be recognized for our meta-analysis. For example, the analysis was limited in fully published studies in English, which probably introduced bias.

In conclusion, this meta-analysis indicated that $S F 3 B 1$ mutation was significantly associated with poor PFS and OS in CLL. It suggests that SF3B1 mutation might be a predictive factor of poor prognosis in patients with CLL. However, more prospective studies with better standardized methods are needed to further confirm the results in this study.

\section{MATERIALS AND METHODS}

\section{Publication search}

The relevant published reports were searched in PubMed, EMBASE, and Web of Science updated to October 2016, with the following terms to search the databases: ("SF3B1" OR "Splicing factor 3B subunit 1") AND ("Chronic lymphocytic leukemia" OR "CLL"). Publication language was restricted to English in this study. Additionally, we also manually examined the reference lists of identified studies for potentially relevant papers.

\section{Study selection}

Two reviewers(ZZ and SC) independently screened the titles and abstracts of articles identified by the literature search, retrieved potentially relevant studies and determined study eligibility. Eligible studies should include the following criteria: (1) the study evaluated the association between $S F 3 B 1$ mutation and the prognosis of patients with CLL; (2) the biomarkers of the study included $S F 3 B 1$; (3) the $S F 3 B 1$ mutation of the study was reported with hazard ratios (HRs) and corresponding 95\% confidence intervals (95\%CIs) or with Kaplan-Meier plots; (4) the outcome was progression free survival (PFS) or overall survival (OS). Data published only in abstract form were excluded. Review articles, commentary articles, and studies with insufficient information for data extraction were also excluded.

\section{Data extraction}

The following data including: the first author, year, source of the study population, mutated and wildtype number of patients included in analysis, detection methods, data extraction methods and HRs with their 95\% CIs for OS and/or PFS were extracted from each eligible study by two investigators. If HRs and their 95\% CIs were not directly reported in the included studies, but the survival curves of $S F 3 B 1$ mutation were presented, we extracted HRs and their 95\% CIs from Kaplan-Meier curves by using a method reported by Tierney et al [36].

\section{Statistical analysis}

For the quantitative aggregation of the survival results, HRs and their 95\% CIs were used to measure the impact of $S F 3 B 1$ mutation on survival of CLL. HRs and their $95 \%$ CIs of the studies were pooled by using Stata software (version 12.0). Heterogeneity of studies was calculated by using $\mathrm{Q}$ test and $\mathrm{I}^{2}$ statistic. If $\mathrm{P}_{\mathrm{Q}}>0.10$ or $\mathrm{I}^{2}<50 \%$, it meant there was no significant heterogeneity among the studies, and the pooled HR was combined by fixed-effect model. Otherwise, random-effect model was used [37]. By convention, an observed HR $>1$ implied a worse prognosis for the $S F 3 B 1$ mutation group. Otherwise, an observed $H R<1$ implied a better prognosis for $S F 3 B 1$ mutation group. The impact of $S F 3 B 1$ mutation on survival of CLL was considered to be statistically significant if the $95 \%$ CI did not overlap with 1 . Sources of heterogeneity were analyzed by subgroup analysis. Sensitivity analysis was performed by sequentially excluding each study in turn to test the stability of the main results. The publication bias in the meta-analysis was assessed by Begg's test and funnel plot. $\mathrm{P}<0.05$ was considered significant for the tests.

\section{ACKNOWLEDGMENTS}

This work was supported by Natural Science Foundation of Xinjiang Uygur Autonomous Region (no. 2016D01C262).

\section{CONFLICTS OF INTEREST}

The authors declare that they have no conflicts of interest. 


\section{REFERENCES}

1. Mulligan CS, Best OG, Mulligan SP; Chronic Lymphocytic Leukaemia Australian Research Consortium. The precursor of chronic lymphocytic leukemia. N Engl J Med. 2009; 360: 2575 .

2. Butler T, Gribben JG. Biologic and clinical significance of molecular profiling in chronic lymphocytic leukemia. Blood Rev. 2010; 24: 135-41.

3. Montillo M, Hamblin T, Hallek M, Montserrat E, Morra E. Chronic lymphocytic leukemia: novel prognostic factors and their relevance for risk-adapted therapeutic strategies. Haematologica. 2005; 90: 391-9.

4. Zenz T, Mertens D, Kuppers R, Dohner H, Stilgenbauer $\mathrm{S}$. From pathogenesis to treatment of chronic lymphocytic leukaemia. Nat Rev Cancer. 2010; 10: 37-50.

5. Rossi D. Chronic lymphocytic leukaemia: new genetic markers as prognostic factors. Hematol Oncol. 2013; 31: $57-9$.

6. Hamblin T. Prognostic factors in chronic lymphocytic leukemia. Leuk Lymphoma. 2006; 47: 2261-2.

7. Podhorecka M, Halicka D, Szymczyk A, Macheta A, Chocholska S, Hus M, Darzynkiewicz Z. Assessment of red blood cell distribution width as a prognostic marker in chronic lymphocytic leukemia. Oncotarget. 2016; 7: 3284653. doi: 10.18632/oncotarget.9055.

8. Li JY, Xu W, Wu YJ, Fan L, Qiu HX, Ruan CG. CD38 as a prognostic factor in Chinese patients with chronic lymphocytic leukaemia. Blood. 2007; 110: 246b.

9. Nipp RD, Volkheimer AD, Davis ED, Chen YW, Weinberg JB, Friedman DR. CD38 variation as a prognostic factor in chronic lymphocytic leukemia. Leuk Lymphoma. 2014; 55: 191-4.

10. Dicker F, Herholz H, Schnittger S, Nakao A, Patten N, Wu L, Kern W, Haferlach T, Haferlach C. The detection of TP53 mutations in chronic lymphocytic leukemia independently predicts rapid disease progression and is highly correlated with a complex aberrant karyotype. Leukemia. 2009; 23: 117-24.

11. Gabus R, Pritsch O, Landoni AI, Bianchi S, Canessa C, Tiscornia A, Borelli G, Uturbey F, Bodega JE. Immunophenotype and immunoglobulin variable genes (IGVH) mutation status in chronic lymphocytic leukemia (CLL). New prognostic patterns detection and target therapy. Blood. 2006; 108: 334b-b.

12. Stamatopoulos B, Meuleman N, Haibe-Kains B, Duvillier H, Massy M, Martiat P, Bron D, Lagneaux L. Quantification of ZAP70 mrna in B cells by real-time PCR is a powerful prognostic factor in chronic lymphocytic leukemia. Clin Chem. 2007; 53: 1757-66

13. Larrayoz M, Blakemore SJ, Dobson RC, Blunt MD, Rose-Zerilli MJJ, Walewska R, Duncombe A, Oscier D, Koide K, Forconi F, Packham G, Yoshida M, Cragg MS, et al. The SF3B1 inhibitor spliceostatin a (SSA) elicits apoptosis in chronic lymphocytic leukaemia cells through downregulation of Mcl-1. Leukemia. 2016; 30: 351-60.

14. Mori J, Takahashi Y, Tanimoto T. SF3B1 in Chronic Lymphocytic Leukemia. N Engl J Med. 2012; 366: 1057.

15. Wan YZ, Wu CJ. SF3B1 mutations in chronic lymphocytic leukemia. Blood. 2013; 121: 4627-34.

16. Wang LL, Lawrence MS, Wan YZ, Stojanov P, Sougnez C, Stevenson K, Werner L, Sivachenko A, DeLuca DS, Zhang L, Zhang WD, Vartanov AR, Fernandes SM, et al. SF3B1 and other novel cancer genes in chronic lymphocytic leukemia. N Engl J Med. 2011; 365: 2497-506.

17. Baliakas P, Hadzidimitriou A, Sutton LA, Rossi D, Minga E, Villamor N, Larrayoz M, Kminkova J, Agathangelidis A, Davis Z, Tausch E, Stalika E, Kantorova B, et al. Recurrent mutations refine prognosis in chronic lymphocytic leukemia. Leukemia. 2015; 29: 329-36.

18. Sutton LA, Young E, Baliakas P, Hadzidimitriou A, Moysiadis T, Plevova K, Rossi D, Kminkova J, Stalika E, Pedersen LB, Malcikova J, Agathangelidis A, Davis Z, et al. Different spectra of recurrent gene mutations in subsets of chronic lymphocytic leukemia harboring stereotyped B-Cell receptors. Haematologica. 2016; 101: 959-67.

19. Xia Y, Fan L, Wang L, Gale RP, Wang M, Tian T, Wu W, Yu L, Chen YY, Xu W, Li JY. Frequencies of SF3B1, NOTCH1, MYD88, BIRC3 and IGHV mutations and TP53 disruptions in Chinese with chronic lymphocytic leukemia: disparities with Europeans. Oncotarget. 2015; 6: 5426-34. doi: 10.18632/oncotarget.3101.

20. Mitsui T, Koiso H, Nakahashi H, Saitoh A, Shimizu H, Ishizaki T, Ogawa Y, Takizawa M, Yokohama A, Saitoh T, Jinbo T, Ogura H, Handa H, et al. SF3B1 and Ighv ene Mutation Status Predict Poor Prognosis in Japanese Cll Patients. Intr J Hematol. 2016; 103: 219-26.

21. Nadeu F, Delgado J, Royo C, Baumann T, Stankovic T, Pinyol M, Jares P, Navarro A, Martin-Garcia D, Bea S, Salaverria I, Oldreive C, Aymerich M, et al. Clinical impact of clonal and subclonal TP53, SF3B1, BIRC3, NOTCH1, and ATM mutations in chronic lymphocytic leukemia. Blood. 2016; 127: 2122-30.

22. Rossi D, Bruscaggin A, Spina V, Rasi S, Khiabanian H, Messina M, Fangazio M, Vaisitti T, Monti S, Chiaretti S, Guarini A, Del Giudice I, Cerri M, et al. Mutations of the SF3B1 splicing factor in chronic lymphocytic leukemia: association with progression and fludarabine-refractoriness. Blood. 2011; 118: 6904-8.

23. Oscier DG, Rose-Zerilli MJ, Winkelmann N, de Castro DG, Gomez B, Forster J, Parker H, Parker A, Gardiner A, Collins A, Else M, Cross NCP, Catovsky D, et al. The clinical significance of NOTCH1 and SF3B1 mutations in the UK LRF CLL4 trial. Blood. 2013; 121: 468-75.

24. Dreger P, Schnaiter A, Zenz T, Bottcher S, Rossi M, Paschka P, Buhler A, Dietrich S, Busch R, Ritgen M, Bunjes D, Zeis M, Stadler M, et al. TP53, SF3B1, and NOTCH1 
mutations and outcome of allotransplantation for chronic lymphocytic leukemia: six-year follow-up of the GCLLSG CLL3x trial. Blood. 2013; 121: 3284-8.

25. Hurtado AM, Chen-Liang TH, Przychodzen B, Hamedi C, Munoz-Ballester J, Dienes B, Garcia-Malo MD, Anton AI, de Arriba F, Teruel-Montoya R, Ortuno FJ, Vicente V, Maciejewski JP, et al. Prognostic signature and clonality pattern of recurrently mutated genes in inactive chronic lymphocytic leukemia. Blood Cancer J. 2015; 5.

26. Stilgenbauer S, Schnaiter A, Paschka P, Zenz T, Rossi M, Dohner K, Buhler A, Bottcher S, Ritgen M, Kneba M, Winkler D, Tausch E, Hoth P, et al. Gene mutations and treatment outcome in chronic lymphocytic leukemia: results from the CLL8 trial. Blood. 2014; 123: 3247-54.

27. Jeromin S, Weissmann S, Haferlach C, Dicker F, Bayer K, Grossmann V, Alpermann T, Roller A, Kohlmann A, Haferlach T, Kern W, Schnittger S. SF3B1 mutations correlated to cytogenetics and mutations in NOTCH1, FBXW7, MYD88, XPO1 and TP53 in 1160 untreated CLL patients. Leukemia. 2014; 28: 108-17.

28. Schnaiter A, Paschka P, Rossi M, Zenz T, Buhler A, Winkler D, Cazzola M, Dohner K, Edelmann J, Mertens D, Kless S, Mack S, Busch R, et al. NOTCH1, SF3B1, and TP53 mutations in fludarabine-refractory CLL patients treated with alemtuzumab: results from the CLL2H trial of the GCLLSG. Blood. 2013; 122: 1266-70.

29. Quesada V, Conde L, Villamor N, Ordonez GR, Jares P, Bassaganyas L, Ramsay AJ, Bea S, Pinyol M, MartinezTrillos A, Lopez-Guerra M, Colomer D, Navarro A, et al. Exome sequencing identifies recurrent mutations of the splicing factor SF3B1 gene in chronic lymphocytic leukemia. Nat Genet. 2012; 44: 47-52.
30. Rossi D, Rasi S, Spina V, Bruscaggin A, Monti S, Ciardullo C, Deambrogi C, Khiabanian H, Serra R, Bertoni F, Forconi F, Laurenti L, Marasca R, et al. Integrated mutational and cytogenetic analysis identifies new prognostic subgroups in chronic lymphocytic leukemia. Blood. 2013; 121: 1403-12.

31. Hirshfield KM, Ali SM, Miller VA, Stephens PJ, Karantza V, DiPaola RS, Rodriguez-Rodriguez L, Ganesan S. Prospective next generation sequencing (NGS) of rare or poor prognosis cancers. Cancer Res. 2014; 74.

32. Berndt SI, Camp NJ, Skibola CF, Vijai J, Wang ZM, Gu J, Nieters A, Kelly RS, Smedby KE, Monnereau A, Cozen W, Cox A, Wang SS, et al. Meta-analysis of genome-wide association studies discovers multiple loci for chronic lymphocytic leukemia. Nat Commun. 2016; 7: 10933.

33. Hallek M; International CLL-IPI working group. An international prognostic index for patients with chronic lymphocytic leukaemia (CLL-IPI): a meta-analysis of individual patient data. Lancet Oncol. 2016; 17: 779-90.

34. Alexander PE, Bonner AJ, Agarwal A, Li SA, Hariharan A, Izhar Z, Bhatnagar N, Alba C, Akl EA, Fei YT, Guyatt GH, Beyene J. Sensitivity subgroup analysis based on singlecenter vs. multi-center trial status when interpreting metaanalyses pooled estimates: the logical way forward. J Clin Epidemiol. 2016; 74: 80-92.

35. Henmi M, Copas JB, Eguchi S. Confidence intervals and $\mathrm{P}$-values for meta-analysis with publication bias. Biometrics. 2007; 63: 475-82.

36. Tierney JF, Stewart LA, Ghersi D, Burdett S, Sydes MR. Practical methods for incorporating summary time-to-event data into meta-analysis. Trials. 2007; 8: 16.

37. DerSimonian R, Laird N. Meta-analysis in clinical trials revisited. Contemp Clin Trials. 2015; 45: 139-45. 